\title{
Economic Impact of Above-Label Dosing with Etanercept, Adalimumab, or Ustekinumab in Patients with Psoriasis
}

\author{
Steven R. Feldman, MD, PhD; Yang Zhao, PhD; Huanxue Zhou, MS; \\ Vivian Herrera, DDS, MPH; Haijun Tian, PhD; and Yunfeng Li, PhD
}

\begin{abstract}
BACKGROUND: Patients with moderate-to-severe psoriasis may be treated with above-label doses of biologics in an attempt to optimize outcomes. Dose escalation will have an effect on the cost of treatment.

OBJECTIVE: To examine costs related to above-label use of etanercept, adalimumab, and ustekinumab among patients with moderate-to-severe psoriasis.

METHODS: A retrospective study was performed using a large U.S. claims database. Patients were included in the study if they were aged $\geq 18$ years with a diagnosis of psoriasis (excluding psoriatic arthritis) and had at least 1 medication fill for etanercept, adalimumab, or ustekinumab between January 1, 2011, and June 30, 2012. In addition, patients were required to have continuous enrollment for 12 months before, and 18 months after, the first biologic use (index biologic) during the maintenance period (defined as the period following the induction period in which each agent was titrated to its recommended maintenance dose per label) and at least 1 prescription filled for the index biologic during the 18 months after the maintenance period. Extensive above-label use was defined as taking an above-label dose (at least $10 \%$ higher than indicated in the label) for $\geq 180$ days over a 12-month period following the maintenance period. Percentages of patients with extensive above-label use, mean number of days of above-label use, and additional costs associated with extensive above-label use (abovelabel cost minus on-label cost) were examined.
\end{abstract}

RESULTS: The study included 3,310 patients who started treatment with etanercept $(n=1,443)$, adalimumab $(n=1,447)$, or ustekinumab $(n=420)$. Extensive above-label use occurred in $20.0 \%$ of etanercept patients, $2.6 \%$ of adalimumab patients, and $14.8 \%$ of ustekinumab patients. The mean duration of extensive above-label use was roughly similar for the 3 biologics (mean days $[ \pm$ SD]: $282[ \pm 55]$ for etanercept, $279[ \pm 57]$ for adalimumab, and $305[ \pm 43]$ for ustekinumab). Additional annual costs per patient because of extensive above-label use were $\$ 19,458$ for etanercept, $\$ 18,972$ for adalimumab, and $\$ 21,045$ for ustekinumab. Total additional annual costs were $\$ 5,623,362$ for etanercept, $\$ 701,964$ for adalimumab, and $\$ 1,304,790$ for ustekinumab.

CONCLUSIONS: Psoriasis patients treated with etanercept, adalimumab, or ustekinumab had extensive above-label use over the 12-month follow-up period, which subsequently led to higher costs.

J Manag Care Spec Pharm. 2017;23(5):583-89

Copyright @ 2017, Academy of Managed Care Pharmacy. All rights reserved.

\section{What is already known about this subject}

Psoriasis is a chronic and immune-mediated skin disease associated with many medical comorbidities and a diminished quality of life. Biologic agents are increasingly used to treat moderate-to-severe psoriasis, but rates of successful treatment are lower in clinical practice than reported in clinical trials, which may lead to dose escalation in the real-world setting.

Biologics are among the most costly therapeutics, and the economic consequences of above-label dosing are not fully characterized.

\section{What this study adds}

Extensive above-label dosing ( $\geq 180$ days over a 12 -month period) occurred in $20.0 \%$ of etanercept patients, $2.6 \%$ of adalimumab patients, and $14.8 \%$ of ustekinumab patients.

The mean duration of extensive above-label use for etanercept, adalimumab, and ustekinumab was over 279 days for 12 months.

Extensive above-label dosing of etanercept, adalimumab, and ustekinumab was associated with additional costs beyond those that would have been incurred with on-label use.

$\mathrm{P}$ soriasis is a chronic, painful, immune-mediated skin disease that affects approximately 7.4 million adults in the United States. ${ }^{1}$ Patients with psoriasis are at increased risk of a wide range of chronic and serious physical and mental health conditions, including psoriatic arthritis, diabetes mellitus, hypertension, cardiovascular disease, stroke, cancer, depression, anxiety, and suicidality. ${ }^{2}$

Patients with psoriasis have significant impairments in quality of life, with almost $60 \%$ in a large-scale survey reporting their disease to be a large problem. ${ }^{3}$ Individuals with extensive skin involvement have been shown to suffer more pronounced reductions in quality of life. ${ }^{4}$ However, even those with less severe disease frequently find that their disorder constitutes a substantial problem in everyday living. ${ }^{3}$

The economic consequences of psoriasis are considerable, marked by significantly higher health care costs than in the general population. ${ }^{5,6} \mathrm{~A}$ recent systematic review of published studies revealed that the total annual cost was as high as $\$ 135$ billion in 2013 dollars, mainly driven by direct costs related to medical care. ${ }^{5}$ The economic burden of psoriasis is of particular 
concern given that this is a lifelong disease, and many patients require continuing treatment. ${ }^{1,5}$

The American Academy of Dermatology guidelines for management of psoriasis provide recommendations for the use of a variety of treatments, depending on the severity of disease. ${ }^{7}$ Moderate-to-severe psoriasis may be treated with topical agents, phototherapy, conventional systemic drugs (primarily methotrexate), and/or biologic agents that target specific cytokines involved in the immunopathology of the disease (e.g., the antitumor necrosis factor agents etanercept and adalimumab and the anti-interleukin [IL]-12/23 agent ustekinumab). A 75\% improvement in Psoriasis Area and Severity Index score from baseline (PASI 75) has served as the primary measure of therapeutic success in clinical trials, although more subjective measures are used in clinical practice. ${ }^{8}$ Newer treatments have improved the ability to attain good control of the disease, with high PASI 75 rates (e.g., $79.6 \%$ for adalimumab vs. $35.5 \%$ for methotrexate at 16 weeks in the phase III CHAMPION study $[P<0.001] ; 67.5 \%$ for ustekinumab $45 \mathrm{mg}$ and $73.8 \%$ for ustekinumab $90 \mathrm{mg}$ vs. $56.8 \%$ for etanercept at 12 weeks in the phase III ACCEPT study $\left[P=0.01\right.$ and $P<0.001$, respectively]). ${ }^{9,10}$

Effective treatment of psoriasis also improves quality of life, as reflected in greater patient satisfaction with outcomes. ${ }^{11}$ The degree of skin clearance is a critical consideration, since greater clearance results in greater improvement in quality of life. ${ }^{8}$ Despite ongoing improvements in the efficacy of systemic treatment for psoriasis, rates of success with commonly used agents (e.g., adalimumab, etanercept, and ustekinumab) are lower in clinical practice than reported in clinical trials. ${ }^{12}$ This lack of effectiveness may result in dosage adjustments in the real-world setting, as clinicians address patient dissatisfaction with treatment outcomes, attempt to improve effectiveness in very severe cases, compensate for increasing dose tolerance over time, or manage patients with obesity for whom standard dosing may not be adequate. ${ }^{13,14}$ A previous study in patients with moderateto-severe psoriasis treated with biologics found that more than one third of patients experienced a dose escalation during the initial year of treatment (defined as any dose escalation over a 12 -month period): etanercept, $41 \%$; adalimumab, 37\%; and ustekinumab. ${ }^{14}$ Because cost-of-treatment estimates are often based on labeled dosing, especially in budget impact and costeffectiveness analyses, it is important to know how often such off-label (and, particularly, above-label) dosing occurs in order to gain a better understanding of real-world costs.

Biologics are among the most costly of therapeutics. ${ }^{15-17}$ However, the economic consequences of above-label dosing with biologics are not fully characterized. The objective of this study was to examine the extensive above-label use $(\geq 180$ days over a 12-month period) of etanercept, adalimumab, and ustekinumab among patients with moderate-to-severe psoriasis in real-world practice, as well as the additional costs associated with above-label use.

\section{TABLE 1 Definitions of Above-Label Dose}

\begin{tabular}{|c|c|c|}
\hline Biologic & $\begin{array}{l}\text { On-Label Maintenance } \\
\text { Dose } \\
\text { 20-22 }\end{array}$ & $\begin{array}{c}\text { Above-Label Dose } \\
(\geq 10 \% \text { recommended dose) }\end{array}$ \\
\hline Etanercept & 50 mg once weekly & $\geq 55 \mathrm{mg}$ weekly \\
\hline Adalimumab & $40 \mathrm{mg}$ every other week & $\geq 22$ mg weekly \\
\hline Ustekinumab & $\begin{array}{l}\text { - Patient }<100 \mathrm{~kg}(<220 \mathrm{lbs}): \\
45 \mathrm{mg} \text { every } 12 \text { weeks } \\
\text { - Patient } \geq 100 \mathrm{~kg}(\geq 220 \mathrm{lbs}): \\
90 \mathrm{mg} \text { every } 12 \text { weeks }\end{array}$ & $\begin{array}{l}\text { - Patient }<100 \mathrm{~kg}(<220 \mathrm{lbs}) \text { : } \\
\geq 49.5 \mathrm{mg} \text { every } 12 \text { weeks } \\
\text { - Patient } \geq 100 \mathrm{~kg} \text { ( } \geq 220 \mathrm{lbs}) \text { : } \\
\geq 99 \mathrm{mg} \text { every } 12 \text { weeks }\end{array}$ \\
\hline
\end{tabular}

\section{Methods}

\section{Study Design}

A retrospective cohort analysis was performed using a large U.S. claims database to examine the above-label use of etanercept, adalimumab, and ustekinumab in patients with moderate-to-severe psoriasis, as well as the associated costs. Data were extracted from the Truven Health MarketScan Commercial Encounters Database (an employer-based claims database that includes fully integrated pharmacy and health care claims records at the patient level for 77.7 million lives) and the Medicare Supplemental Database (which captures information for 6.7 million lives) between January 1, 2010, and December 31, 2013.

\section{Patient Selection}

Psoriasis patients (International Classification of Diseases, Ninth Revision, Clinical Modification [ICD-9-CM] code 696.1) aged 18 years and older who had at least 1 claim for a biologic of interest (etanercept, adalimumab, or ustekinumab; subsequently designated as the index biologic) between January 1, 2011, and June 30, 2012, were identified. To meet the definition for continuous biologic use, patients were also required to have continuous pharmacy benefits for 12 months before and 18 months after the first use of the index biologic during the maintenance period (defined as the period following the induction period in which each agent was titrated to its recommended maintenance dose per label). The duration of induction periods ranged from 2 to 12 weeks. ${ }^{14}$ Patients were further required to have at least 1 prescription filled for the index biologic during the "lookforward period" (extending for 18 months following the end of the maintenance period) to ensure that patients were was on continuous treatment with the index biologic).

Patients were excluded from the analysis if they switched to a different biologic or had any record of the following specified diagnoses (ICD-9-CM): psoriatic arthritis (696.0), rheumatoid arthritis (714.x), ankylosing spondylitis (720.0), Crohn's disease (555.x), juvenile idiopathic arthritis (714.3), ulcerative colitis (556.8), human immunodeficiency virus (042.x), or cancer (140.x-239.x). Patients were also excluded if they had missing HCPCS (Healthcare Common Procedure Coding System) information regarding medication dosage or days of supply. 


\section{Inclusion criteria}

$\geq 1$ claim for biologic of interest between January 1, 2011, and June 30, 2012

Continuous enrollment in medical and pharmacy benefits program from 1 year before starting biologic to 18 months after achieving maintenance does

Diagnosis of psoriasis within 1 year of starting biologic

$\geq 1$ prescription filled for the index biologic during the 18 months after the maintenance period to be eligible for continuous treatment

\section{Exclusion criteria}

Diagnosis of psoriatic arthritis, rheumatoid arthritis, ankylosing spondylitis, Crohn's disease, juvenile idiopathic arthritis, ulcerative colitis, HIV, or cancer

Switch to another biologic after starting biologic of interest

Age $<18$ years

Missing HCPCS information (drug dosage/days of supply)

Use of a different biologic within 12 months before initiation of continuous therapy with biologic of interest

Final study population

Maintenance period began before June 30, 2012

\begin{tabular}{|c|c|c|}
\hline Etanercept & Adalimumab & Ustekinumab \\
\hline $\begin{array}{c}59,470 \\
\downarrow\end{array}$ & $\begin{array}{c}59,137 \\
\downarrow\end{array}$ & $\begin{array}{c}5,542 \\
\quad \downarrow\end{array}$ \\
\hline $\begin{array}{c}27,135 \\
\Downarrow\end{array}$ & $\underset{26,745}{\downarrow}$ & $\begin{array}{c}2,438 \\
\downarrow\end{array}$ \\
\hline $\begin{array}{c}7,063 \\
\downarrow\end{array}$ & $\begin{array}{c}7,193 \\
\downarrow\end{array}$ & $\begin{array}{c}2,333 \\
\quad \downarrow\end{array}$ \\
\hline 4,777 & 4,864 & 1,664 \\
\hline$\downarrow$ & $\downarrow$ & $\downarrow$ \\
\hline $\begin{array}{c}1,782 \\
\downarrow\end{array}$ & $\begin{array}{c}1,948 \\
\downarrow\end{array}$ & $\begin{array}{c}857 \\
\downarrow\end{array}$ \\
\hline $\begin{array}{c}1,691 \\
\downarrow\end{array}$ & $\begin{array}{c}1,876 \\
\downarrow\end{array}$ & $\begin{array}{c}835 \\
\downarrow\end{array}$ \\
\hline $\begin{array}{c}1,667 \\
\downarrow\end{array}$ & $\begin{array}{c}1,857 \\
\downarrow\end{array}$ & $\begin{array}{c}834 \\
\downarrow\end{array}$ \\
\hline $\begin{array}{c}1,646 \\
\downarrow\end{array}$ & $\begin{array}{c}1,845 \\
\downarrow\end{array}$ & $\begin{array}{c}\mathrm{N} / \mathrm{A} \\
\downarrow\end{array}$ \\
\hline$\stackrel{1,549}{\mid}$ & $\stackrel{1,582}{a}$ & 439 \\
\hline $\begin{array}{c}\downarrow \\
1,443\end{array}$ & $\begin{array}{c}\downarrow \\
1,447\end{array}$ & $\begin{array}{c}\downarrow \\
420\end{array}$ \\
\hline
\end{tabular}

Ustekinumab was identified by National Drug Code and J-code, so there was no exclusion for patients billed with J-code in the data.

HCPCS = Healthcare Common Procedure Coding System; HIV=human immunodeficiency virus; N/A = not applicable.

\section{Outcomes Assessments}

The primary outcomes for this analysis were the percentage of patients with extensive above-label use of a biologic, mean number of days of above-label use, and additional costs associated with extensive above-label use. Above-label use was defined as a dose at least $10 \%$ higher than indicated in the label based on pharmacy claims data for each patient during the specified time interval (Table 1). For each prescription filled, information regarding strength per unit, number of units, and supply days were used to calculate daily dose based on the following formula:

Daily dose $=($ strength of unit $) \times($ number of units $) \div$ supply days

Extensive above-label use was defined as taking an abovelabel dose for $\geq 180$ days (consecutive or nonconsecutive) over a 12 -month period following the maintenance period. Additional costs were examined in terms of excess costs per patient per day (above-label biologic treatment cost minus on-label biologic treatment cost captured in the paid amount, which includes costs reimbursed to the providers from the insurance, as well as patient out-of-pocket payments); additional annual costs per patient among individuals with extensive above-label use (excess costs per patient per day multiplied by the number of days with above-label use); and total additional annual costs associated with extensive above-label use (additional annual costs per patient multiplied by the number of patients with extensive above-label use).

\section{Data Analyses}

Patient demographics, percentage of patients with extensive above-label use, mean days of above-label use, and additional costs associated with extensive above-label use were examined for etanercept, adalimumab, and ustekinumab over the 12-month follow-up period after the maintenance period. Twotail nonparametric tests were conducted to assess pairwise differences on patient demographics (age, gender, and region) and baseline health care costs over 12 months before biologic initiation, with $P<0.05$ considered as statistical significance. All costs were adjusted to 2014 U.S. dollars based on the medical care component of the Consumer Price Index. Sensitivity analyses were performed using alternative threshold definitions of above-label use (i.e., $\geq 30, \geq 60, \geq 90, \geq 120$, or $\geq 150$ days).

\section{Results}

\section{Patient Characteristics}

A total of 3,310 patients met the study criteria and were included in the analysis (Figure 1). Treatment was started with etanercept in 1,443 patients, adalimumab in 1,447, and ustekinumab in 420. The mean (standard deviation [SD]) age ranged from 46.4 (12.1) to 49.0 (12.4) years, and the percentage of males ranged from $56.0 \%$ to $65.3 \%$ (Table 2). Statistically significant $(P<0.05)$ differences were seen among the 3 treatment groups with respect to mean age, age distribution, gender, and region. Mean total psoriasis-related costs over the 12 months before 
TABLE 2 Patient Characteristics

\begin{tabular}{|c|c|c|c|}
\hline & $\begin{array}{c}\text { Etanercept } \\
\mathrm{n}=1,443\end{array}$ & $\begin{array}{c}\text { Adalimumab } \\
\mathbf{n}=1,447\end{array}$ & $\begin{array}{c}\text { Ustekinumab } \\
n=420\end{array}$ \\
\hline \multicolumn{4}{|l|}{ Demographics } \\
\hline Mean age, years, mean $( \pm S D)^{a}$ & $\begin{array}{c}49.0 \\
( \pm 12.4)\end{array}$ & $\begin{array}{c}46.4 \\
( \pm 12.1)\end{array}$ & $\begin{array}{c}46.9 \\
( \pm 13.0)\end{array}$ \\
\hline \multicolumn{4}{|l|}{ Age group, $\%$ b } \\
\hline $18-24$ years & 2.8 & 4.9 & 5.2 \\
\hline $25-34$ years & 10.5 & 12.4 & 11.9 \\
\hline $35-44$ years & 22.5 & 25.6 & 25.5 \\
\hline $45-54$ years & 30.8 & 30.1 & 27.9 \\
\hline 55-64 years & 24.8 & 22.4 & 22.6 \\
\hline$\geq 65$ years & 8.7 & 4.6 & 6.9 \\
\hline Male, $\%^{c}$ & 65.3 & 62.5 & 56.0 \\
\hline \multicolumn{4}{|l|}{ Region, \% ${ }^{\mathrm{d}}$} \\
\hline Northeast & 14.3 & 10.2 & 16.9 \\
\hline North Central & 28.2 & 26.7 & 23.8 \\
\hline South & 39.4 & 46.5 & 45.7 \\
\hline West & 17.6 & 16.0 & 12.9 \\
\hline \begin{tabular}{l|l} 
Unknown \\
\end{tabular} & 0.5 & 0.5 & 0.7 \\
\hline \multicolumn{4}{|l|}{ Health care costs, mean $( \pm$ SD)e } \\
\hline All-cause total ${ }^{f}$ & $\begin{array}{c}\$ 22,921 \\
( \pm \$ 14,776)\end{array}$ & $\begin{array}{c}\$ 19,130 \\
( \pm \$ 15,562)\end{array}$ & $\begin{array}{c}\$ 24,412 \\
( \pm \$ 30,777)\end{array}$ \\
\hline Psoriasis-related total ${ }^{\mathrm{f}}$ & $\begin{array}{c}\$ 16,948 \\
( \pm \$ 11,239)\end{array}$ & $\begin{array}{c}\$ 12,720 \\
( \pm \$ 9,317)\end{array}$ & $\begin{array}{c}\$ 15,596 \\
( \pm \$ 14,688)\end{array}$ \\
\hline Biologic costsg & $\begin{array}{c}\$ 16,588 \\
( \pm \$ 11,248)\end{array}$ & $\begin{array}{c}\$ 12,282 \\
( \pm \$ 9,327)\end{array}$ & $\begin{array}{c}\$ 12,750 \\
( \pm 14,759)\end{array}$ \\
\hline
\end{tabular}

aTwo-tail nonparametric tests were conducted to assess pairwise differences: $P<0.05$ for adalimumab and ustekinumab versus etanercept.

${ }^{b}$ Two-tail nonparametric tests were conducted to assess pairwise differences: $P<0.05$ for adalimumab versus etanercept.

CTwo-tail nonparametric tests were conducted to assess pairwise differences: $P<\hat{A} 0.05$ for etanercept versus ustekinumab.

${ }^{d}$ Two-tail nonparametric tests were conducted to assess pairwise differences: $P<0.05$ for etanercept and ustekinumab versus adalimumab.

eBaseline costs adjusted to year 2014 U.S. dollars based on the medical care component of the Consumer Price Index.

fTotal health care costs include medical costs plus prescription drug costs. Two-tail nonparametric tests were conducted to assess pairwise differences, with $P<0.05$ for all comparisons except for comparison on all-cause total for etanercept versus ustekinumab.

STwo-tail nonparametric tests were conducted to assess pairwise differences, with $P<0.05$ for all comparisons.

biologic initiation ranged from $\$ 12,720$ to $\$ 16,948$, and mean biologic costs ranged from $\$ 12,282$ to $\$ 16,588$.

\section{Extensive Above-Label Biologic Use and Associated Costs}

Extensive above-label use occurred in $20.0 \%$ of etanercept patients, $2.6 \%$ of adalimumab patients, and $14.8 \%$ of ustekinumab patients (Figure 2). The mean duration $( \pm S D$ ) of above-label use among patients with extensive above-label use was roughly similar for the 3 biologics: $282( \pm 55)$ days for etanercept, $279( \pm 57)$ days for adalimumab, and $305( \pm 43)$ days for ustekinumab. The additional costs per patient per day with extensive above-label biologic use were $\$ 69$ for etanercept, $\$ 68$ for adalimumab, and $\$ 64$ for ustekinumab (data not shown). Additional annual costs per patient were $\$ 19,458$ for etanercept, $\$ 18,972$ for adalimumab, and $\$ 21,045$ for ustekinumab. Total additional annual costs associated with extensive above-label use were $\$ 5,623,362$ for etanercept, $\$ 701,964$ for adalimumab, and $\$ 1,304,790$ for ustekinumab.

The sensitivity analyses confirmed the results from the primary analyses (Figure 3). The percentage of patients with above-label use declined with higher alternative threshold definitions (from $\geq 30$ days to $\geq 150$ days): percentages decreased from $33.4 \%$ to $22.8 \%$ for etanercept, from $5.1 \%$ to $2.9 \%$ for adalimumab, and from $22.9 \%$ to $16.4 \%$ for ustekinumab. The mean duration $( \pm S D)$ of above-label use was high for all alternative definitions, ranging from $211( \pm 100)$ to $268( \pm 64)$ days for etanercept, 185 ( \pm 108$)$ to $266( \pm 65)$ days for adalimumab, and $228( \pm 113)$ to $291( \pm 59)$ days for ustekinumab. The additional annual costs per patient increased with higher alternative definitions of above-label use, ranging from $\$ 14,559$ to $\$ 18,492$ for etanercept, $\$ 12,580$ to $\$ 18,088$ for adalimumab, and $\$ 15,732$ to $\$ 20,079$ for ustekinumab. The total additional annual costs declined with higher alternative threshold definitions for above-label use, decreasing from $\$ 7,017,438$ to $\$ 6,083,868$ for etanercept, $\$ 930,920$ to $\$ 759,696$ for adalimumab, and $\$ 1,510,272$ to $\$ 1,385,451$ for ustekinumab.

\section{Discussion}

Psoriasis has a significant impact on patients' lives., ${ }^{5,18}$ Before the availability of biologics, treatment of moderate-to-severe psoriasis relied on medications such as methotrexate and cyclosporine, drugs with considerable toxicity. With these older agents, the end goal of treatment was to attain a reasonable degree of disease control/improvement, not clearance of psoriatic plaque. If skin clearance was seen, doses were lowered to avoid toxicity. The advent of biologics targeting specific signaling molecules involved in psoriasis pathogenesis has revolutionized psoriasis treatment, providing safer and more effective options; as a result, achieving high levels of clearance is no longer an unrealistic goal. Biologics have also revolutionized the cost of psoriasis treatment. The high cost of these agents adds to the pressure for all parties to be wise and responsible stewards of limited medical resources. In recent years, cost-effectiveness data for psoriasis treatments have been used to guide treatment and coverage policies. Cost models frequently rely on the labeled dose of medication to determine cost-effectiveness. Patients, however, are often treated with doses outside the standard labeling. Such dosing can have a large effect on the cost of treatment. To assess the practical question of cost-effectiveness in a real-world setting, real-life dosing patterns must be considered.

Using a large, recent, U.S. claims database analysis, this study provides insights into extensive above-label use of biologics in patients with moderate-to-severe psoriasis and documents resultant costs exceeding those that 


\section{FIGURE 2 Extensive Above-Label Biologic Use and Associated Costs}

\section{A. Percentage of Patients}

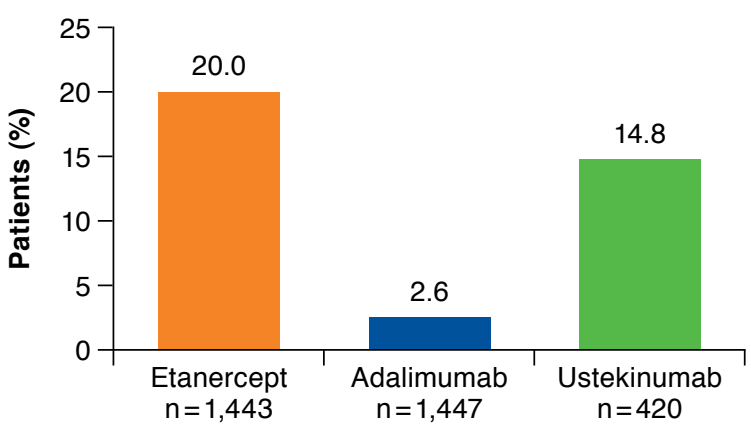

C. Additional Annual Cost per Patient

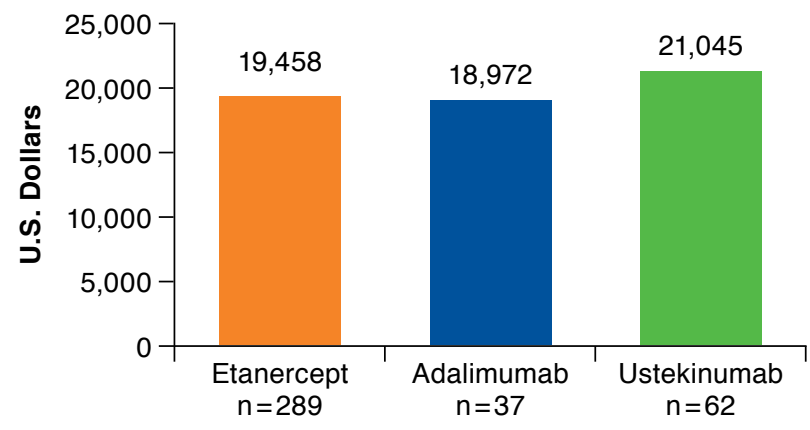

B. Mean Duration of Above-Label Use

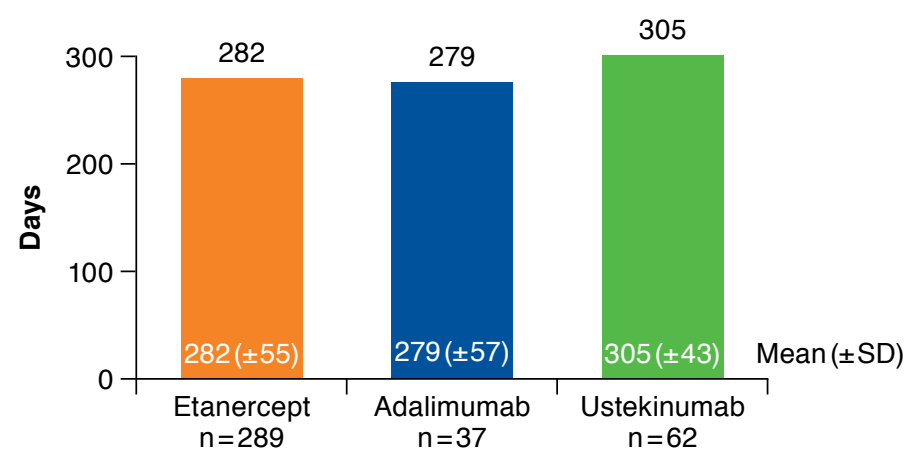

D. Total Additional Annual Costs

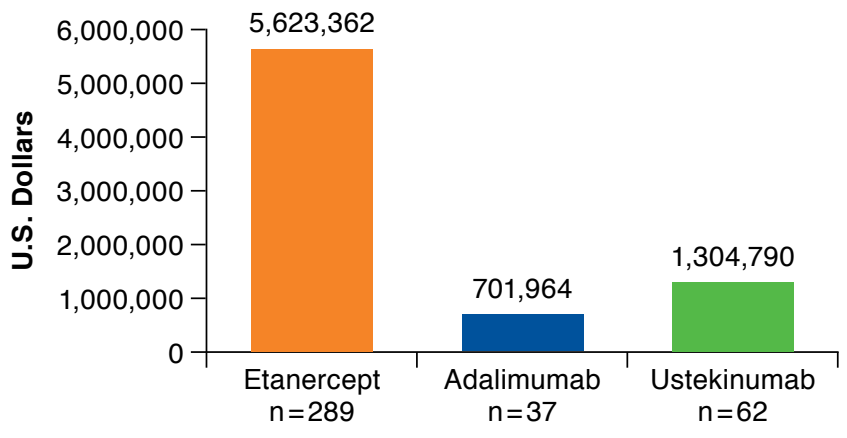

would have been incurred with on-label use. Patients with moderate-to-severe psoriasis treated with etanercept, adalimumab, and ustekinumab had extensive above-label use over the 12 months of treatment. The mean duration of extensive abovelabel use was high with all 3 biologics and exceeded 275 days over the 12-month follow-up period. Extensive above-label use of biologics was associated with additional annual costs per patient that approached or exceeded $\$ 20,000$. The total additional annual cost associated with extensive above-label dosing was highest with ustekinumab, followed by etanercept and adalimumab. Because the additional costs assessed in this study only capture the extra treatment costs, the increased medical costs, office visits, and adverse events/costs due to worsened side effects of above-label dosing are not included. The real additional total costs associated with above-label dosing will be higher than reported in this study, and future studies are needed to look into the overall economic impact.

It is interesting to note that extensive above-label use was substantially less prevalent with adalimumab (2.6\%) as compared with etanercept (20\%) and ustekinumab (14.8\%). Our pharmacy claims database approach does not allow us to speculate whether this may be a result of differential efficacy or other factors. Dosing approved by the U.S. Food and
Drug Administration is based on achieving optimal treatment benefits for the overall psoriasis population, and it is possible that some individuals might require higher dosing to achieve the same result; such individual variations may also have played a role in our findings. This subject warrants further research, since it clearly has implications for maximizing the cost-effectiveness of biologic therapy.

Management of the cost of psoriasis treatment may be facilitated by the development of new treatments that target more specific psoriasis immune pathways and reduce side effects. Clinical trials of IL-17 antagonists have shown persistent high levels of efficacy over long periods of time, potentially minimizing the necessity for dose escalation. The costs of abovelabel dosing, which are highlighted by this study, should be considered when making cost-effective choices among the many options now available for individual patients and for population-based coverage decisions.

\section{Limitations}

This study has several limitations. First, the number of patients in the ustekinumab group was small. Second, various categories of information that may have affected or provided insight into study outcomes (such as measures of disease severity/treatment 
FIGURE 3 Sensitivity Analyses: Above-Label Biologic Use and Associated Costs Using Alternative Threshold Definitions ( $\geq 30$ to $\geq 150$ Days)

A. Percentage of Patients

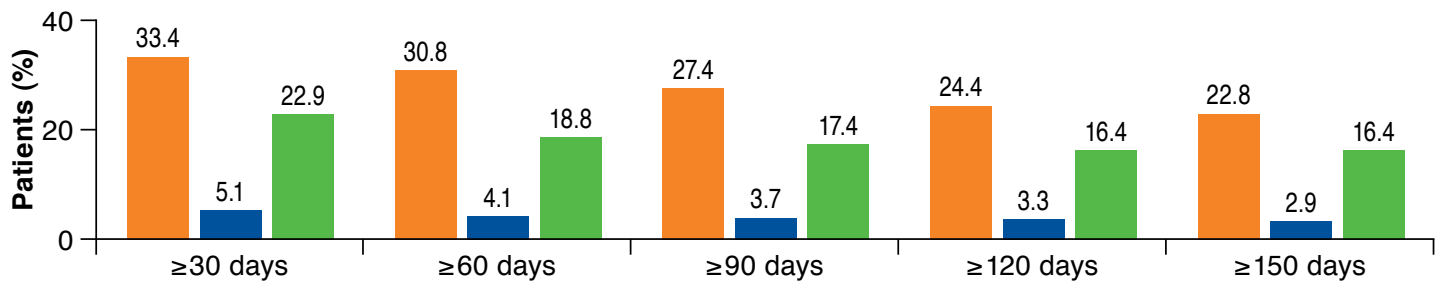

B. Mean Duration of Above-Label Use

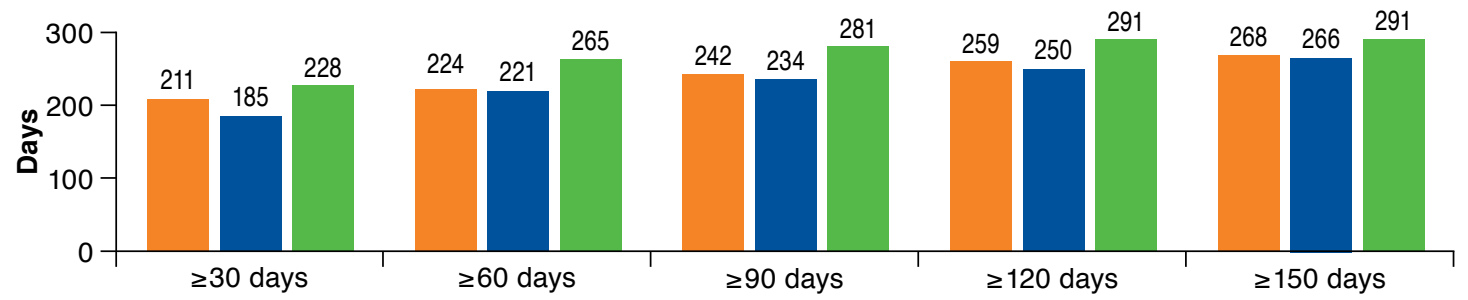

C. Additional Annual

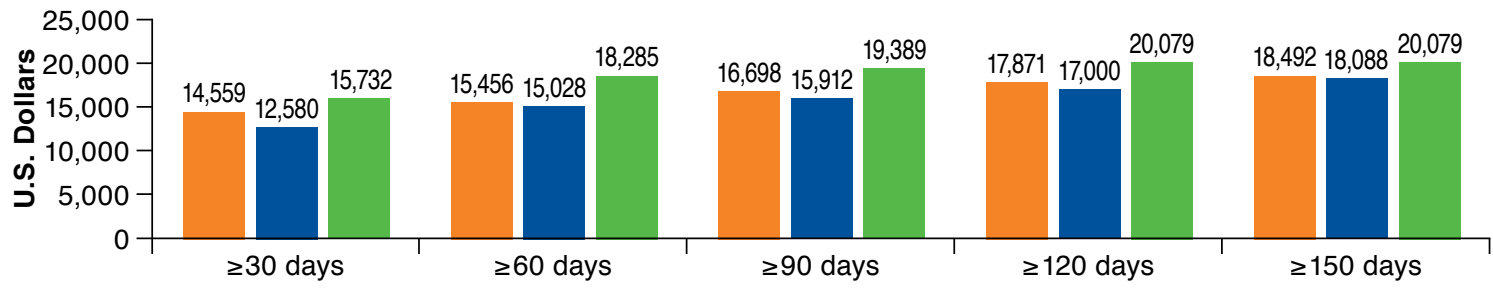

D. Total Additional

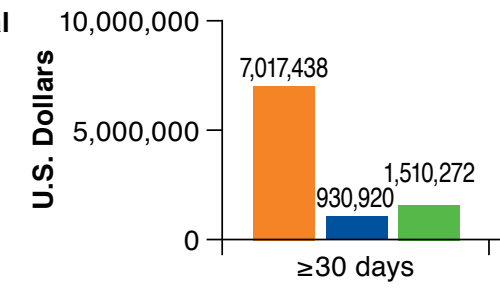

Annual Costs

Etanercept, number of patients
Adalimumab, number of patients
Ustekinumab, number of patients

482
74
96

$\begin{array}{ll}445 & 395 \\ 59 & 54 \\ 79 & 73\end{array}$

Etanercept $\quad$ Adalimumab Ustekinumab

efficacy, socioeconomic status, frequency of dosing, and allergy profiles) were not available in the claims. The claims database also did not report patient body weight, an important criterion in selecting a ustekinumab dose. Additionally, this study only focused on the economic impact of extensive above-label dosing and did not assess comorbidities or previous or concurrent immunosuppressants or other agents used to treat psoriasis, which could help explain why patients had above-label dosing. Third, as with most retrospective claims analyses, it is possible that there may have been miscoding of diagnoses, resource use services, or procedures, leading to potential errors in estimation. Finally, the patient cohorts were determined from a database encompassing employees, their spouses and dependents who were covered by large employer-sponsored private health insurance plans, and individuals with Medicare supplemental coverage. As a result, the findings reported here may not be generalizable to the entire U.S. population.

\section{Conclusions}

This study used a large, recent U.S. claims database to examine the costs associated with extensive above-label use of biologics in patients with moderate-to-severe psoriasis. The results 
showed that patients with psoriasis who were treated with etanercept, adalimumab, or ustekinumab had extensive use of above-label doses over a 12-month follow-up period, which led to higher costs than would have been incurred with on-label use of these biologics.

\section{Authors}

STEVEN R. FELDMAN, MD, PhD, Wake Forest University School of Medicine, Winston-Salem, North Carolina. YANG ZHAO, PhD, U.S. Health Economics \& Outcomes Research; VIVIAN HERRERA, DDS, MPH, U.S. Health Economics \& Outcomes Research; HAIJUN TIAN, PhD, CoE for Real World Evidence; and YUNFENG LI, PhD, U.S. Health Economics \& Outcomes Research, Novartis Pharmaceuticals Corporation, East Hanover, New Jersey. HUANXUE ZHOU, MS, Health Economics \& Outcomes Research, KMK Consulting, Morristown, New Jersey.

AUTHOR CORRESPONDENCE: Yang Zhao, PhD, Director, U.S. Health Economics \& Outcomes Research, Novartis Pharmaceuticals Corporation, One Health Plaza, East Hanover, NJ 07936-1080. Tel.: 862.778.3662; E-mail: yang-3.zhao@novartis.com.

\section{DISCLOSURES}

Novartis Pharmaceuticals Corporation sponsored this study and the resultant publication. BioScience Communications provided medical writing and editorial support, which was also funded by Novartis Pharmaceuticals Corporation. Feldman was engaged by Novartis Pharmaceuticals as a paid clinical expert and scientific advisor for this study. He has received research support and speaking and/or consulting fees from AbbVie, Advance Medical, Amgen, Anacor, Astellas, Baxter, Boehringer Ingelheim, Caremark, Celgene, Eli Lilly, Galderma, GSK/Stiefel, Informa, Janssen, LEO Pharma, Merck, Merz, Mylan, National Biological, National Psoriasis Foundation, Pfizer, Qurient, Suncare Research, UpToDate, and Valeant; is the founder and majority owner of www.DrScore.com; and is founder and part owner of Causa Research. Zhao, Herrera, Tian, and Li are employees of Novartis Pharmaceuticals. Zhou is a paid consultant for Novartis Pharmaceuticals and is an employee of KMK Consulting.

Study concept and design were contributed by Feldman, Zhao, Herrera, and Li. Zhou and Li were responsible for data collection. Data were interpreted by Feldman and Zhao, with assistance from Zhou, Herrera, Tian, and Li. The manuscript was written primarily by Feldman and Zhao, with assistance from Zhou and Li. The manuscript was revised by Feldman and Zhao, assisted by Zhou, Herrera, Tian, and Li.

Portions of this work were presented at the 34th Anniversary Fall Clinical Dermatology Conference in Las Vegas, Nevada, October 1-4, 2015.

\section{REFERENCES}

1. Rachakonda TD, Schupp CW, Armstrong AW. Psoriasis prevalence among adults in the United States. J Am Acad Dermatol. 2014;70(3):512-16.

2. Feldman SR, Zhao Y, Shi L, Tran MH. Economic and comorbidity burden among patients with moderate-to-severe psoriasis. J Manag Care Spec Pharm. 2015;21(10):874-88. Available at: http://www.jmcp.org/doi/10.18553/ jmcp.2015.21.10.874.

3. Stern RS, Nijsten T, Feldman SR, Margolis DJ, Rolstad T. Psoriasis is common, carries a substantial burden even when not extensive, and is associated with widespread treatment dissatisfaction. J Investig Dermatol Symp Proc. 2004:9(2):136-39.
4. Gelfand JM, Feldman SR, Stern RS, Thomas H, Rolstad T, Margolis DJ. Determinants of quality of life in patients with psoriasis: a study from the U.S. population. J Am Acad Dermatol. 2004;51(5):704-08.

5. Brezinski EA, Dhillon JS, Armstrong AW. Economic burden of psoriasis in the United States: a systematic review. JAMA Dermatol. 2015;151(6):651-58. 6. Vanderpuye-Orgle J, Zhao Y, Lu J, et al. Evaluating the economic burden of psoriasis in the United States. J Am Acad Dermatol. 2015;72(6):961-67.e5. 7. Menter A, Korman NJ, Elmets CA, et al; for the American Academy of Dermatology Work Group. Guidelines of care for the management of psoriasis and psoriatic arthritis: section 6 . Guidelines of care for the treatment of psoriasis and psoriatic arthritis: case-based presentations and evidencebased conclusions. J Am Acad Dermatol. 2011;65(1):137-74.

8. Puig L. PASI90 response: the new standard in therapeutic efficacy for psoriasis. J Eur Acad Dermatol Venereol. 2015;29(4):645-48.

9. Saurat JH, Stingl G, Dubertret L, et al; for the CHAMPION Study Investigators. Efficacy and safety results from the randomized controlled comparative study of adalimumab vs. methotrexate vs. placebo in patients with psoriasis (CHAMPION). Br J Dermatol. 2008;158(3):558-66.

10. Griffiths CE, Strober BE, van de Kerkhof P, et al. Comparison of ustekinumab and etanercept for moderate-to-severe psoriasis. N Engl J Med. 2010;362(2):118-28

11. Callis Duffin K, Yeung H, Takeshita J, et al. Patient satisfaction with treatments for moderate-to-severe plaque psoriasis in clinical practice. Br J Dermatol. 2014;170(3):672-80.

12. Gelfand JM, Wan J, Callis Duffin K, et al. Comparative effectiveness of commonly used systemic treatments or phototherapy for moderate to severe plaque psoriasis in the clinical practice setting. Arch Dermatol. 2012;148(4):487-94.

13. Brezinski EA, Armstrong AW. Off-label biologic regimens in psoriasis: a systematic review of efficacy and safety of dose escalation, reduction, and interrupted biologic therapy. PLoS One. 2012;7(4):e33486.

14. Feldman SR, Zhao Y, Navaratnam P, Friedman HS, Lu J, Tran MH. Patterns of medication utilization and costs associated with the use of etanercept, adalimumab, and ustekinumab in the management of moderate-tosevere psoriasis. J Manag Care Spec Pharm. 2015;21(3):201-09. Available at: http://www.jmcp.org/doi/10.18553/jmcp.2015.21.3.201.

15. Bonafede MM, Gandra SR, Watson C, Princic N, Fox KM. Cost per treated patient for etanercept, adalimumab, and infliximab across adult indications: a claims analysis. Adv Ther. 2012;29(3):234-48.

16. Schabert VF, Watson C, Gandra SR, Goodman S, Fox KM, Harrison DJ Annual costs of tumor necrosis factor inhibitors using real-world data in a commercially insured population in the United States. J Med Econ. 2012;15(2):264-75.

17. Schabert VF, Watson C, Joseph GJ, Iversen P, Burudpakdee C, Harrison DJ. Costs of tumor necrosis factor blockers per treated patient using real-world drug data in a managed care population. J Manag Care Pharm. 2013;19(8):621-30. Available at: http://www.jmcp.org/doi/10.18553/ jmcp.2013.19.8.621

18. Armstrong AW, Schupp C, Bebo B. Psoriasis comorbidities: results from the National Psoriasis Foundation surveys 2003 to 2011. Dermatology. 2012;225(2):121-26.

19. Kurd SK, Troxel AB, Crits-Christoph P, Gelfand JM. The risk of depression, anxiety and suicidality in patients with psoriasis: a population-based cohort study. Arch Dermatol. 2010;146(8):891-95.

20. Enbrel (etanercept) solution for subcutaneous use. Amgen. Revised November 2016. Available at: http://pi.amgen.com/united_states/enbrel/ derm/enbrel_pi.pdf. Accessed March 29, 2017.

21. Humira (adalimumab) injection, subcutaneous use. AbbVie. Revised October 2016. Available at: http://www.rxabbvie.com/pdf/humira.pdf. Accessed March 29, 2017.

22. Stelara (ustekinumab) injection, for subcutaneous use. Janssen Biotech. Revised September 2016. Available at: http://www.stelarainfo.com/pdf/ PrescribingInformation.pdf. Accessed March 29, 2017. 